\title{
Adoption of Virtual Technology to the Development of a BIM based PMIS
}

\author{
Suh, Bong-Gyo ${ }^{1}$ Lee, Ghang ${ }^{2}$ Yun, Seok-Heon ${ }^{3 *}$ \\ Department of Architectural Engineering, Graduate School Gyeongsang National University, Gazwa-dong, Jinju-si, \\ Gyeongsangnam-do, Korea ${ }^{1}$ \\ Department of Architectural Engineering, Yonsei University, SinChon-dong, Seoul, Korea ${ }^{2}$ \\ Department of Architectural Engineering, Engineering Research Institute, Gyeongsang National University, \\ Gazwa-dong, Jinju-si, Gyeongsangnam-do, Korea ${ }^{3}$
}

\begin{abstract}
As construction projects become bigger, PMIS is being used as a project collaboration tool for project participants, owners, designers, inspectors and contractors. As the data type used in PMIS is usually text and most PMIS have no standard information classification system, there is a problem with data usability, such as the capacity for data search and analysis. BIM uses Objects and Properties, and this information might be used for relating with other construction information. As such, BIM technologies can be used with PMIS to enhance the data usability. The web environment is very convenient for multiple users, but the problem is that the data transfer speed is low for big files such as BIM model files. In this study, we suggested a Virtual Technology (VT) application to enhance the performance of BIM data exchange in PMIS, and tested and analyzed its efficiency when it is used to integrate BIM and PMIS in the web environment. The results of the study showed that VT can be used to enhance the efficiency of BIM data exchange in the web environment.
\end{abstract}

Keywords : building information model, project management information system, virtual technology

\section{Introduction}

\subsection{Research objective}

The construction industry has a life cycle that includes several phases, such as planning, design, construction, and maintenance, in which the participants in charge of each phase must cooperate with each other for the successful completion of a construction project. As such, there has been an urgent need for an integrated system that can manage potential jobs and tasks from the beginning to the end of a project. Project

Received : September 18, 2012

Revision received : June 11, 2013

Accepted : June 28, 2013

* Corresponding author : Yun, Seok-Heon

[Tel: 055-772-1755, E-mail: gfyun@gnu.ac.kr]

(c)2013 The Korea Institute of Building Construction, All rights reserved.
Management Information System (PMIS), an information system for construction project management, has been built and used. However, there are no clear information classification criteria for the PMS, and the management has been performed based on the information of whether it is a text or a file, which leads to terribly low usability of information as a result[1].

With recent advancements in IT, the progress of a construction project can be simulated in advance in a 3D virtual environment by using the Building Information Model (BIM) to predict and derive possible problems before construction. In addition, a more advanced technology is now being used that allows more accurate work process planning based on the work simulation[2].

BIM technology shares a similarity with PMIS, in that the related information can be integrated and 
managed over almost the entire range of a construction project, from the planning to the design, construction and maintenance. Some efforts have been made to integrate the PMIS with the BIM technologies; however, integration has magnified some problems, including incompatibility among information types and the massive exchange of BIM information on the Internet. For this reason, this study aims to analyze the problems found in the process of developing a BIM-based PMIS, and present an improved version of a BIM-based PMIS through the application of the virtualization technology, which has been suggested as a solution to the problems associated with the massive exchange of BIM information via the Internet.

\subsection{Research methodology and scope}

The previous studies on PMIS and BIM-based PIMS were examined to determine the connectability of PMIS with BIM and to analyze the problems arising from such connection.

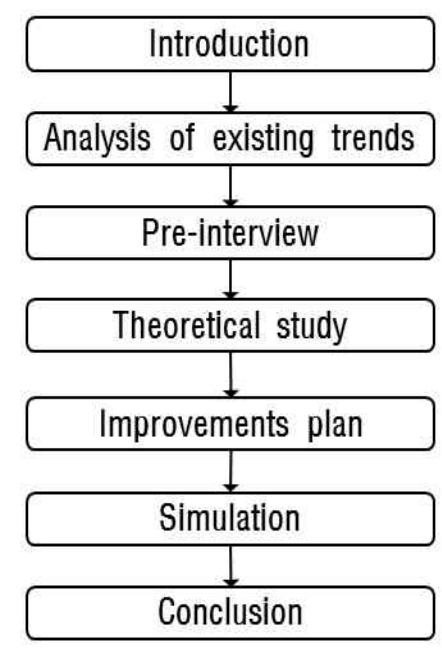

Figure 1. The process of the study

Next, a virtualization technology was proposed to solve the problems associated with the massive exchange of BIM data on the Internet. In addition, the applicability of the virtualization technology was verified through a prototype system and a commercial program. More specifically, the in-house developed IFC-based construction simulation program and Navisworks, a commercial program, were used to verify the applicability. The process of this research can be summarized as shown in Figure 1.

\section{Review of previous studies}

\subsection{Research trends in PMIS and BIM}

PMIS has been developed as a collaborative tool for information provision and smooth communication among participants. Recently, some PMISs have been made that also provide a management function for collaboration and resources. It is an effective system for a construction project, but it requires that a detailed review of the design and review of constructability be conducted through an additional file transfer. For this reason, it needs to be improved to allow a more effective exchange of visual information without any file transfer.

With the introduction of the solution and concept of BIM, studies have been actively conducted to increase productivity and collaboration by equipping the system with a real-time site monitoring function and a more efficient management function, making more diversified programs compatible in addition to management-oriented programs, and implementing more effective data accumulation. The cases shown in Table 1 are solutions for higher productivity and improved collaboration that introduce the solution and concept of BIM technologies to PMIS. In other words, they attempt to resolve such problems as disconnection of information flow and the simple accumulation and sorting of information in a database that have been reported in previous PMIS and PMIS-related studies. However, these were all fundamental 
studies that proposed a conceptualized plan but lacked any concrete methodology for building the system.

Table 1. Previous studies on PMIS

\begin{tabular}{ccc}
\hline Division & Researcher & \multicolumn{1}{c}{ Research contents } \\
\hline PMIS & Kim et al.[3] & $\begin{array}{l}\text {-Suggest an improved scheme of domestic } \\
\text { PMIIS through case study. }\end{array}$ \\
Kim[4] & $\begin{array}{c}\text {-Suggest Application of effective planning in } \\
\text { PMMIS through analyzing obstacle to build } \\
\text { PMIS. }\end{array}$ \\
\hline $\begin{array}{c}\text { PMIS } \\
\text { based } \\
\text { on BIM }\end{array}$ & $\begin{array}{c}\text { Moon et.[5] } \\
\text { al.[6] }\end{array}$ & $\begin{array}{l}\text {-Deliver a direction through analysis of the } \\
\text { correlation between BIM and PMIS. }\end{array}$ \\
$\begin{array}{c}\text {-Deduct a problem existing PMIS } \\
\text {-Suggests the ways for applying BPMS based } \\
\text { on PMIS. } \\
\text { Yoon et } \\
\text { al.[7] }\end{array}$ & $\begin{array}{c}\text {-Suggest strategy for BIM+PMIS system } \\
\text { focused on improving PMIS based on ASP. }\end{array}$ \\
\hline
\end{tabular}

\subsection{Current state of studies on BIM data exchange}

The International Alliance for Interoperability (IAI) developed the Industrial Foundation Classes (IFC) as a standard information model for the expression, storage, exchange and sharing of the information on building structures to secure compatibility and interoperability between diverse BIM tools, and IFC 2x3 was released in 2007 and is used as the current standard[8]. Table 2 lists the previous studies on BIM data compatibility.

Table 2. Previous studies on BIM data compatibility

\begin{tabular}{|c|c|}
\hline Researcher & Research contents \\
\hline Jung[8] & $\begin{array}{l}\text { A Review on Exchange of Building Design } \\
\text { Information based on IFC }\end{array}$ \\
\hline Chin et al.[9] & $\begin{array}{l}\text { IFC test between commercial 3D CAD application } \\
\text { using IFC }\end{array}$ \\
\hline $\operatorname{Kim}[10]$ & $\begin{array}{c}\text { A Study on the Interoperability Test and Model } \\
\text { Improvement Bentley BIM Data through IFC } \\
\text { system }\end{array}$ \\
\hline Jeong[11] & $\begin{array}{c}\text { A study of efficient BIM data exchange and } \\
\text { sharing }\end{array}$ \\
\hline Joana[12] & $\begin{array}{c}\text { Interaction and Visual Simulation in A Construction } \\
\text { Environment }\end{array}$ \\
\hline
\end{tabular}

Chin et al. presented a methodology to make IFC object models as a database and improve IFC files for secure compatibility through the IFC test and evaluation[9]. Kim et al. proposed an improvement plan by measuring data compatibility at the design phase with the three BIM models - Bentley Architecture (BTA), ArchiCAD (ARC), and Revit Architecture (RVT), which are commercial 3D CAD applications - using the IFC extracted from BTA, and analyzing the problems found[10]. Jeong revealed the performance assessment results of BUCKY and presented an object-oriented database method as an alternative[11].

Joana proposed a 4D simulation prototype for updating construction schedule changes with the progress of a construction project, and analyzed its performance[12].

Most of the studies focused on data compatibility, and few studies have been conducted on the massive information exchange required for a BIM-based PMIS.

\section{A building plan for a BIM-based PMIS}

\subsection{Operation process for a BIM-based PMIS}

The basic process for a BIM-based PMIS can be defined as follows. First of all, the volume and resource information is defined in a 3D Modeling, and the work breakdown structure is made, based on which the master schedule is planned and corrected through a simulation, and then overall constructability is reviewed using the detailed simulations of weekly/monthly schedules. At this time, the BIM data created is systemically categorized to enable users to exchange and share it via a PMIS.

If BIM information is provided to a web-based PMIS, the reduction in construction duration, prevention of safety accidents and cost reductions can be expected by simulating the interference check between the processes at a construction site and accurately analyzing the volume of resources. In addition, through the analysis of before and 
after construction simulations and construction progress, the extent to which the construction has progressed can be checked using the visualized progression bar on the screen, without visiting the site.

If these kinds of information are systematically sorted and stored in the database for PMIS, the information can be reused for the building maintenance. The information created from other documents, information and the construction site can be accumulated either as technology or as knowledge information in a PMIS, and then utilized for a new project. The process is outlined in Figure 2.

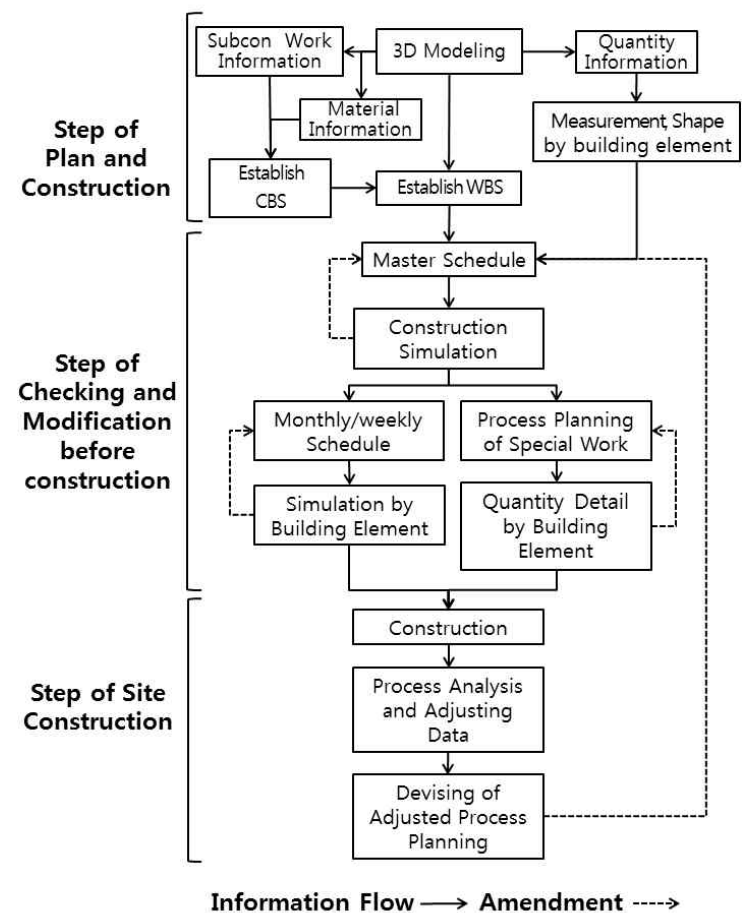

Figure 2. BIM based PMIS process

\subsection{User satisfaction with the utilization of PMIS and BIM}

In this section, problems were analyzed by surveying current users on the current state of information use via a PMIS and the questionnaires on BIM information use. 50 questionnaires or 68 percent of all those distributed were collected. The questionnaire consisted of 11 design-related questions and 23 construction-related questions. First of all, Figure 3 shows the results of the survey on the problems of information use in PMIS. Through the analysis, it was revealed that 38 percent of all respondents identified insufficient practical work support as a problem, making it the most-identified problem, followed by insufficient information classification (24\%) and lack of a data search and utilization function (19\%) in that order. These results show that a PMIS has problems not only with practical work support but also with data search and analysis.

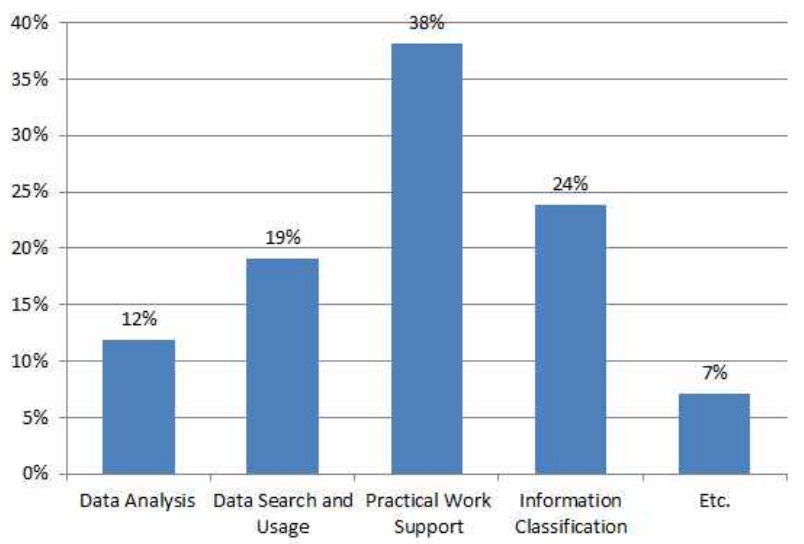

Figure 3. Information use problem in PMIS

Next, the BIM information use was analyzed by surveying BIM Tool users, and Figure 4 shows the analytical results. These results indicate that approximately 50 percent of users see massive data volume and the data exchange between BIM Tools as significant information use problems.

In terms of the massive volume of a file, the larger and the more complex the building is, the more serious the problem. In terms of BIM data exchange, the problem was shown to be magnified when the text-based IFC format was used for the IBM data exchange. 


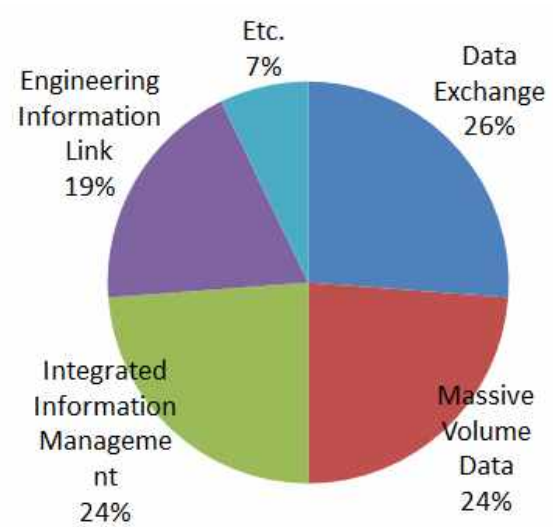

Figure 4. Information use problem in BIM

If a web-based PMIS user needs to download a massive volume of IFC model data every time he/she needs it, it will greatly undermine the usability. To use BIM information and function, the data exchange function of the web-based model should be improved more than anything else, and the introduction of virtual technology was proposed as a solution for the problem.

\subsection{Application of virtual technology}

The proposed virtual technology is similar to a cloud service in that it divides a physical resource into several logical resources or integrates several logical resources into one for use.

As shown in Figure 5, several users share a model server when using an existing PMIS, and they need to download a massive volume of IFC model data whenever they need it. At this time, the usability of the model varies greatly depending on the user's computer capacity. However, the model file is on a high-performance server when using the virtual technology. The user who needs the file can access the server using a virtual technology. At this time, the user can see what he wanted to view, the result image pre-processed on the server, without downloading anything. This means that the user can see the same image as he/she does in the existing PMIS. In addition, the user can see an almost identical view regardless of the capacity of his/her computer.

The usability of virtual technology depends primarily on the $3 \mathrm{D}$ processing performance of the server and the data transfer performance of the network.

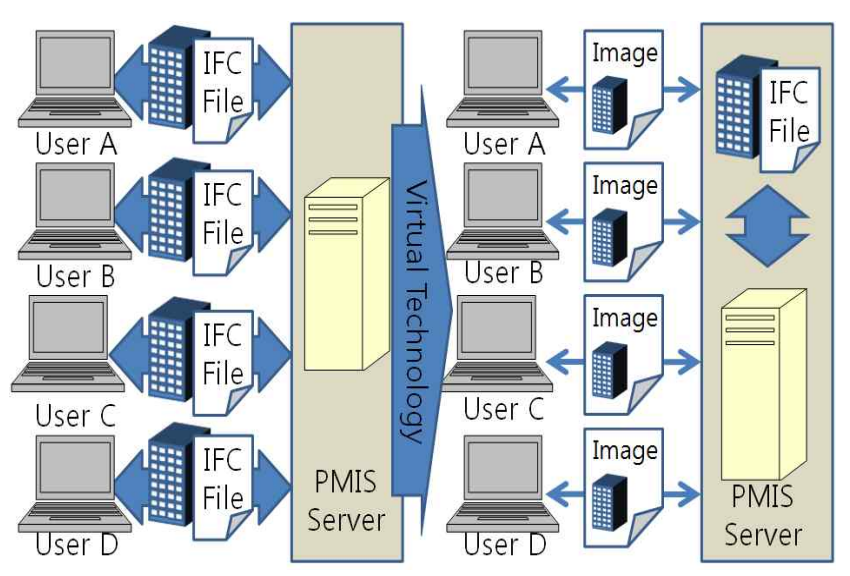

Figure 5. Application of virtualization technology

\section{Implementation of a BIM-based PMIS using the virtual technology}

So far there has been no BIM-based PMIS, but in this study the PMIS is assumed to be built using a BIM-based simulation environment, and an application of virtual technology is proposed to display a model on a client's computer.

Much effort has been made to use the BIM information as a business management tool, including process management. However, in most cases the data is used after being directly downloaded using a stand-alone program like Navisworks. A BIM model is utilized by several users for different purposes, and the usability of BIM information is greatly deteriorated when a user uses individual model information while running a stand-alone program. 


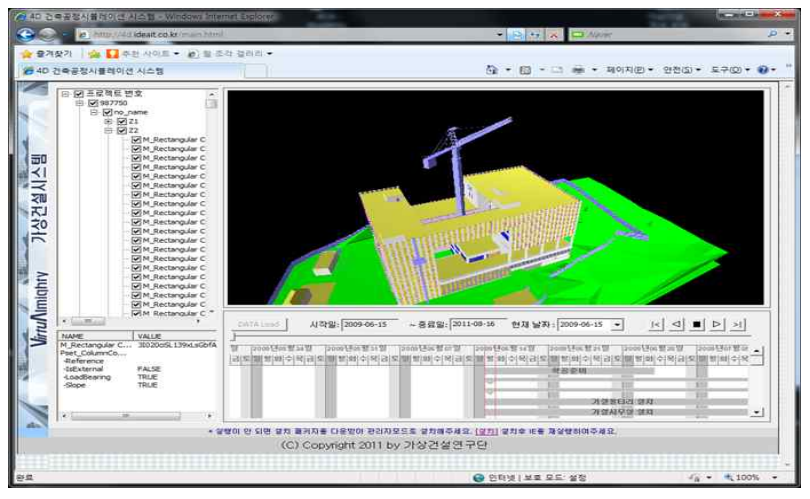

Figure 6. Simulation system using Web environment and IFC

Figure 6 shows the web-based construction simulation on the IFC model viewer developed for this study using web components. To do this, it took a significant amount of time to load the massively large IFC file at the initial loading.

If the web components are installed on the server, and the client computer uses the model information through virtual access, only the image that is needed will be loaded rather than the entire massive volume of the model data, which will result in a reduced downloading time.

This method can be applied not only to the web components but also to a stand-alone program. When the model is loaded through a virtual access after the stand-alone program like Naviworks is installed, the remote client computer can get the view the user wants immediately, without loading massive data.

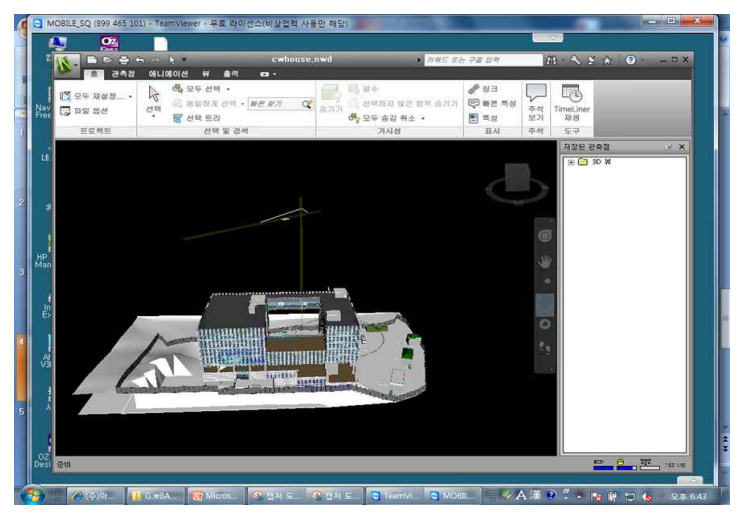

Figure 7. Simulation system using virtual technology
Figure 7 shows Navisworks, a commercial program, run remotely by virtual technology.

In this study, four different types were defined to compare the display performance of the model when using virtual technology, as shown in Table 3.

Table 3. Experimental method

\begin{tabular}{ccccc}
\hline Division & A type & B type & C type & D type \\
\hline File format & IFC & Navisworks & IFC & Navisworks \\
Environment & Web & Web & Virtualization & Virtualization \\
$\begin{array}{c}\text { Schedule } \\
\text { Linking }\end{array}$ & Automatic & Automatic & Automatic & $\begin{array}{c}\text { Manual } \\
\text { Linking }\end{array}$ \\
IFC Support & Possible & Impossible & Possible & Possible \\
Test & (1) & (2) & (3) & (4) \\
\hline
\end{tabular}

In type A, the data was loaded directly using IFC-based web components without using the virtual technology. In type $\mathrm{B}$, the data was directly loaded on the Internet using Navisworks, commercial software. In types $\mathrm{C}$ and $\mathrm{D}$, the data loading was the same as in types A and B, respectively, but the virtual technology was applied both to type $\mathrm{C}$ and type $\mathrm{D}$.

\subsection{Comparison of 4D in the web environment}

The performance of the four different types of simulation method mentioned previously was analyzed by referring to the data loading speed. As illustrated in Figure 8, the speed of virtual technology-based simulations was improved by about 2.5 times on average compared with the web-based simulations. Here, the speed of Navisworks was shown to be higher than that of IFC components because the data volume of Navisworks uses binary type data, which greatly reduces the data volume to $1 / 20$ that of IFC. 


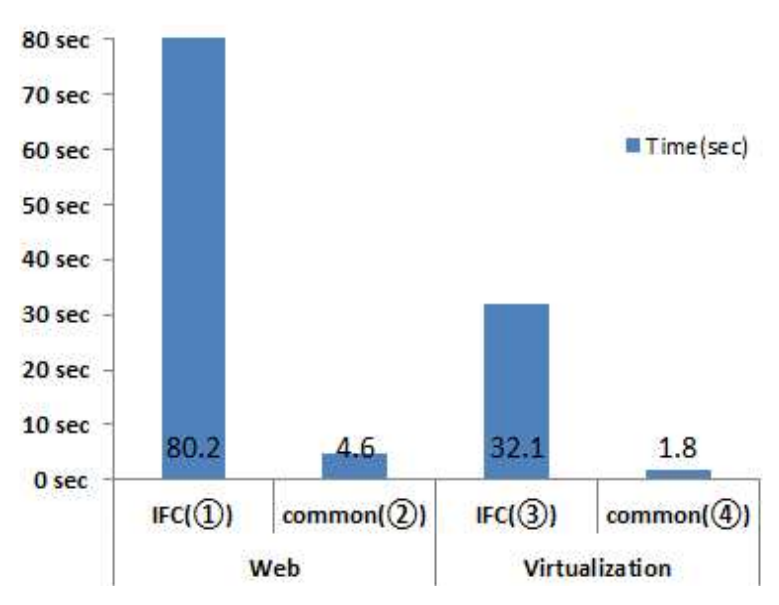

Figure 8. Data file loading speed

\subsection{Process performance evaluation by users}

In addition to the simple loading speed, to analyze the simulation performance in different environments, the simulation-driven workflow was defined as in Figure 10.

In this study, it was designed so that a user would get a simulation result by running the simulation program in the user's desired tab on the menu, loading the data and performing a simulation by linking processes after the start of PMIS and access. For the measurement, each of ten users performed the simulation three times, and the data flow was divided based on whether the virtual technology was used or not and whether processes were linked automatically or not after the data was loaded.

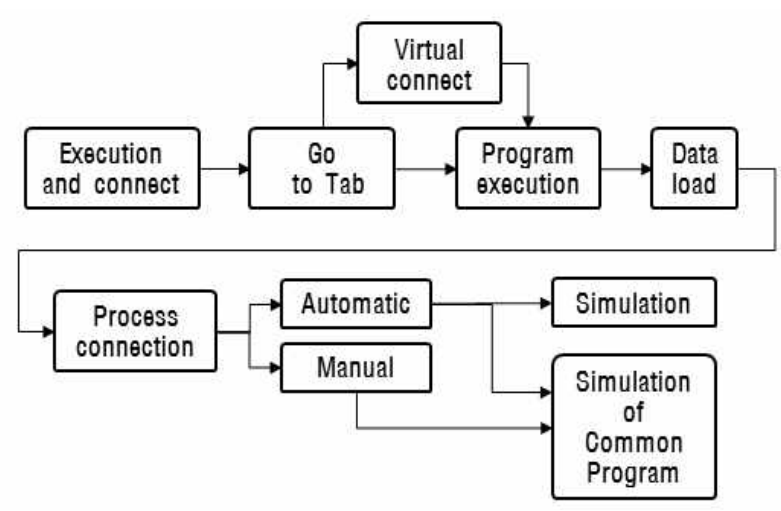

Figure 9. Simulation-driven workflow
The results are shown in Figure 10. The time taken to load the data was considerably shortened, as the earlier test showed. The reduction in time taken resulted from the differences in process flow between web components and remote virtual access methods. That is, remote virtual access and program execution are believed to have consumed more time in the process.

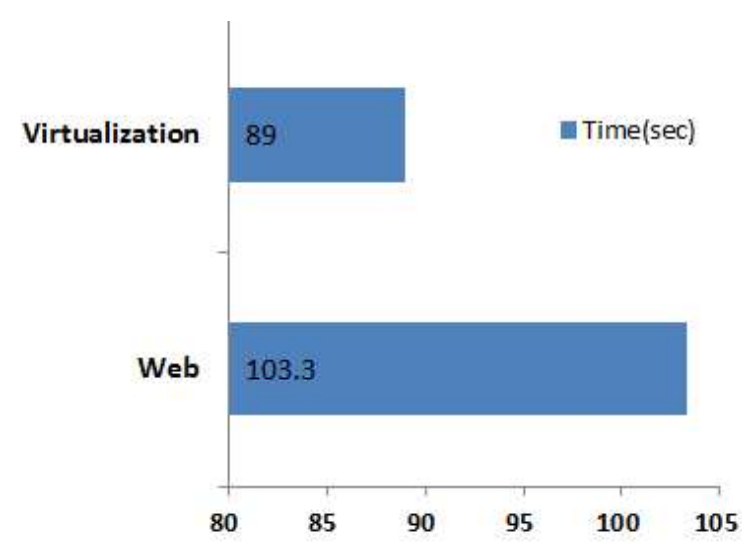

Figure 10. Results of test time

\section{Conclusion}

In this study, the virtual technology was presented to link PMIS with the BIM-based information, and four different prototypes of a web-based construction simulation system were designed to analyze the performance of the proposed method. Through the test, the data loading speed of the remote virtualization was shown to be 2.5 times faster than in the web components method. In the process performance evaluation by users, the virtual environment showed a 13.8 percent improvement compared with the conventional method.

It is revealed that virtual technology can improve BIM data exchange performance on the web. In the future, the performance could possibly be further improved through the model server and data optimization, and on this basis it is believed 
that BIM information can be effectively utilized in the PMIS.

\section{Acknowledgement}

This research was supported by a grant(2011-001585) from National Research Foundation of Korea.

\section{References}

1. Park CS. A Study on the Improvement for Efficient Model of PMIS [master's thesis]. [Busanv (Korea)]: Pukyong National University; 2009. 86 p.

2. Azhar S, Hein M, Sketo B. Building Information Moeling(BIM):Benefit, Risks and Challenges. Proceedings of the $44^{\text {th }}$ ASC National Conference; 2008 April 2-5; Auburn University. Auburn, Alabama: University of Southern Mississippi; 2008. 11 p.

3. Kim JG, Hyun KM, Kim W, Kim OK. Example Analysis and Development of Project Management Information System-Case Study of Subway Construction in D. Area. Journal of Architectural Institute of Korea. 2005 Nov;11(1):593-6.

4. Kim $\mathrm{JH}$. Effective Application of PMIS through Analysis of Barriers At the Development of PMIS. Journal of Korea Institute of Building Construction. 2005 Dec;5(4):107-15.

5. Jeon SH, Yun SH, Paek JH. A Study on Analysis of the Correlation between Building Information Modeling and Project Management Information System. Journal of Architectural Institute of Korea. 2007 Oct;27(1):757-60.

6. Moon SW, Kwon KN, Kim SD. Jung, JH. Application of BIM-based PMIS Considering Construction Life-Cycle. Proceedings of Korea Institute of Construction Engineering and Management; 2008 November 7-8; Korea Unversity (Korea). Seoul (Korea): KICEM; 2008. p. 655-8.

7. Yoon SW, Chin SY, Shin TH, Choi CH. A Strategy for Building BIM+PMIS System. Proceedings of Korea Institute of Construction Engineering and Management; 2008 November 7-8; Korea University. Seoul (Korea): KICEM; 2008. p. 75-81.

8. Jung $J H$. A Review on Exchange of Building Design Information based on IFC. Computational Structural Engineering Institute of Korea. Proceedings of the Computational Structural Engineering Institute Conference; 2009 April 16-17; Jeongseon (Korea). Seoul (Korea):
COSEIK; 2009. p. 68-71.

9. Lim JI, Kim JW, Kwon HD, Yoon SW, Kwon SW, Chin SY. IFC test between commercial 3D CAD application using IFC. Journal of Korea Institute of Construction Engineering and Management. 2008 Jun;9(3):85-94.

10. Kim JW. A Study on the Interoperability Test and Model Improvement Bentley BIM Data through IFC system[master's thesis]. [Seoul (Korea)]: Seoul National University of Science \& Technology; 2009. 63 p.

11. Jeong JY. A study of efficient BIM data exchange and sharing [master's thesis]. [Seoul (Korea)]: Yonsei University; 2010. 56 p.

12. Joana Prata dos Santos. Interaction and Visual Simulation in A Construction Environment. $1^{\text {st }}$ International Conference on Pervasive and Embedded Computing Communication System; 2011 March 5-7; Vilamoura (Portugal). Portugal: SciTePress; 2011. p. 545-50. 